\title{
Design and Characterization of Nanocrystals of Lovastatin for Solubility and Dissolution Enhancement
}

Basavaraj K. Nanjwade*, Ganesh K. Derkar, Hiren M. Bechra, Veerendra K. Nanjwade and F.V. Manvi

Department of Pharmaceutics, KLE University's College of Pharmacy, Belgaum-590010, Karnataka, India

\begin{abstract}
A major hurdle in pharmaceutical formulation is water insolubility of most of the drugs affecting stability and bioavailability of the drug, if the drug is also insoluble in organic medium, it is difficult to deliver the drug in a sufficiently bioavailable form and hence it is a great challenge to formulation researchers to overcome such difficulty. Although some approaches are available for enhancing the dissolution of poorly soluble drugs but has certain draw backs like low drug loading and large doses. However, a new solution to poorly water soluble drug candidates is now available i.e. nanonisation and it leads to much more soluble, more biologically available and safer dosage form of poorly soluble and poorly bioavailable drugs. In the present work, a nanocrystal of lovastatin was formulated by using simple precipitation method without using stabilizer or surfactant and it was found that formulation at $3 \mathrm{mM}$ concentration of drug with the acetone and methanol as a solvent and at proper dilution (50 times) of drug solution with water, nanocrystals with less particle size is possible with slight change in crystallinity. It has also shown that, the drug has enhanced saturation solubility, increased dissolution rate and more bioavailable in biological fluid when drug formulated by using acetone and methanol as a solvent. Whereas drug formulation with acetonitrile has large particle size, less saturation solubility and low rate of dissolution.
\end{abstract}

Keywords: Insolubility; Lipophilic; Nanocrystal; Precipitation method; Lovastatin; Formulation; Crystallinity

\section{Introduction}

Aqueous solubility is one of the key determinants in development of new chemical entities as successful drugs. However, new drug development technologies, such as combinational chemistry and high throughput screening are based on the basic principles of medicinal chemistry, teaching that the most reliable method to increase in vitro potency is to add lipophilic moiety at appropriate position of the lead structure. This has led to an increase in the number of lipophilic and poorly soluble molecules being investigated for their therapeutic activity. Various formulation techniques are applied to compensate for their insolubility and consequent slow dissolution rate. These include formulation of the amorphous solid form, nanoparticles, microemulsions, solid dispersion, melt extrusion, salt formation and formation of water soluble complexes [1] .

Therapeutic effectiveness of a drug depends upon the bioavailability and ultimately upon the solubility of drug molecules. Solubility is one of the parameter to achieve desired concentration of drug in systemic circulation for pharmacological response to be shown. Currently only $8 \%$ of new drug candidates have both high solubility and permeability. It has been estimated that roughly $40 \%$ of all investigational compounds fail development because of poor bioavailability that is often associated with aqueous insolubility (Prentis et al,. 1998). On average, according to the tufts center for the study of drug development, only five out of every 5000 potential drugs are actually tested in clinical trials, and of these only one will eventually be approved for use in patients [2].

In the recent years, nanoparticle technology has emerged as a strategy to tackle such formulation problems associated with poorly water soluble and poorly water and lipid soluble drugs. The reduction of drug particle to the nano-scale increases dissolution velocity and saturation solubility, which leads to improved in vivo drug performance [3].

Hence the next step was taken to improve saturation solubility, dissolution velocity and thereby improving bioavailability of drugs by reducing the particle size from micron size to nano size level, one such approach to increase the solubility of such problematic drugs is the nanonisation.

Lovastatin (LVS) a highly lipophilic but poorly water soluble drug belonging to the class statins, widely used for the treatment of hypercholesterolemia, was used as a model drug due to its poor solubility in water and low bioavailability.

The present study was carried out to develop nanocrystals of lovastatin in order to enhance solubility, dissolution and bioavailability by decreasing the particle size of the drug. In concern to this approach, the primary necessity is to reduce the particle size by precipitation process and solubility and dissolution profiles of obtained nanocrystals were compared with pure drug.

Three formulations of lovastatin nanocrystals were prepared without the use of stabilizer or surfactant and evaluated for particle size, morphology, solubility to confirm the increase in solubility of formulation as compared to pure drug, crystalline state was also assayed by using X-Ray Diffraction and DSC analysis, in vitro release study and in vivo bioavailability were also carried out to observe the effect of different solvent on the release of formulation against pure drug.

\section{Materials and Methods}

\section{Materials}

Lovastatin was supplied by Kreb’s Biochemical pvt. Ltd., Hyderabad.

${ }^{*}$ Corresponding author: Dr. Basavaraj K. Nanjwade, Department of Pharmaceutics KLE University's College of Pharmacy, Belgaum - 590010, Karnataka, India, Tel: 00919742431000; Fax: 00918312472387; E-mail: bknanjwade@yahoo.co.in

Received December 04, 2010; Accepted January 24, 2011; Published February 24, 2011

Citation: Nanjwade BK, Derkar GK, Bechra HM, Nanjwade VK, Manvi FV (2011) Design and Characterization of Nanocrystals of Lovastatin for Solubility and Dissolution Enhancement. J Nanomedic Nanotechnol 2:107. doi:10.4172/21577439.1000107

Copyright: (C) 2011 Nanjwade BK, et al. This is an open-access article distributed under the terms of the Creative Commons Attribution License, which permits unrestricted use, distribution, and reproduction in any medium, provided the original author and source are credited. 
Citation: Nanjwade BK, Derkar GK, Bechra HM, Nanjwade VK, Manvi FV (2011) Design and Characterization of Nanocrystals of Lovastatin for Solubility and Dissolution Enhancement. J Nanomedic Nanotechnol 2:107. doi:10.4172/2157-7439.1000107

Page 2 of 7

Acetone, methanol and acetonitrile were supplied by Rankem laboratories, Mumbai.

\section{Preparation of nanocrystals of lovastatin}

The nanocrystals were prepared by precipitation method. The preparation process involves two steps [4].

i) Preparation of drug solution in organic solvents: $3 \mathrm{mM}$ concentration of drug solution was prepared by preparing solution of drug in organic solvent (based on solubility of drug in particular solvent).

ii) Addition of drug solution in water: Nanocrystals were prepared by adding the microliter quantity of drug solution to milliliter quantity of water quickly with continuous stirring on magnetic stirrer at $1000 \mathrm{rpm}$ (Amount of drug solution added to water should be 10 100 times less than the volume of water). Solvent was removed by overnight stirring at $500 \mathrm{rpm}$. Then it was centrifuged at $5000 \mathrm{rpm}$ and the product was solidified by freeze drying.

\section{Particle morphology}

Nanocrystal formulation was examined using Jeol JSM-840A scanning electron microscope (Japan). The surface morphology of nanocrystal formulation was examined at $\mathrm{P}^{\mathrm{H}}$ 7.4. The samples were mounted on aluminum mount and then were critical point dried, sputter-coated with $9 \mathrm{~nm}$ of gold/palladium and imaged using scanning electron microscope [5].

\section{Particle size analysis}

Particle size of the nanocrystal formulation was done by using particle size analyzer (Nanotrac 150 US). Size and size distribution of the particles in dried state following water redispersion were determined through particle size analyzer with a wet sampling system and the diameters reported were calculated using mean particle size distribution [5].

Crystalline state evaluation: Crystalline state evaluation of nanocrystal formulation was done by using Powder X-Ray diffraction (PXRD) and Differential Scanning Colorimeter (DSC) [5]

Powder X-ray diffraction (PXRD): PXRD diffractograms of each formulation and pure drug were recorded using Philips analytical XRD PW3710 with a $\mathrm{Cu}$ line as source of radiation. Standard runs using a $40 \mathrm{Kv}$ voltage, a $25 \mathrm{~mA}$ current and a scanning rate of $1^{\circ} \mathrm{min}^{-1}$ over $2 \theta$ range of $10-70^{\circ}$ were used.

Differential scanning calorimetry (DSC): Thermal properties of the powder samples were investigated with a Perkin-Elmer DSC-7 differential scanning calorimeter. The amount of product to be analyzed shall range from 4 to $7 \mathrm{mg}$ and be placed in crimped aluminum sealed $50 \mu \mathrm{l}$ pans. Heat runs for each sample has been set from 50 to $300^{\circ}$ at a scanning rate of $10^{\circ} \mathrm{min}^{-1}$, under dry nitrogen flow $(100 \mathrm{ml} / \mathrm{min})$.

Solubility determination of formulation: Solubility of lovastatin nanocrystal formulations were tested in different solvents such as distilled water, acid buffer $\left(\mathrm{P}^{\mathrm{H}} 1.2\right)$ and phosphate buffer $\left(\mathrm{P}^{\mathrm{H}} 7.4\right)$. An excess amount of lovastatin nanocrystal formulation was added in 150 $\mathrm{ml}$ of the pertinent solvents. The mixtures were stirred in a mechanical shaker for 24 hours. Visual inspection was carefully made to ensure there were excess lovastatin solids in the mixture, indicating saturation had been reached. The mixtures were then filtered using $0.45 \mu \mathrm{m}$ millipore filter and filtrates were diluted suitably to determine the solubility of lovastatin in each solvent [6].

\section{In vitro release study}

The release rate of lovastatin nanocrystal was determined using USP Dissolution testing apparatus II (Basket type). The dissolution test was performed using $900 \mathrm{ml}$ of $\mathrm{P}^{\mathrm{H}} 1.2 \mathrm{Buffer}$, at $37 \pm 0.5^{\circ}$ and $50 \mathrm{rpm}$. A sample $(5 \mathrm{ml})$ of the solution was withdrawn from the dissolution apparatus every $15 \mathrm{~min}$ interval for first $1 \mathrm{~h}$ and with Phosphate buffer $\mathrm{P}^{\mathrm{H}} 7.4$ containing $0.25 \% \mathrm{w} / \mathrm{v}$ of sodium lauryl sulphate as a dissolution medium at every $30 \mathrm{~min}$ interval for next $2 \mathrm{~h}$. The samples were replaced with fresh dissolution medium. The samples were filtered and suitably diluted. Absorbance values of these solutions were measured against respective buffer solutions at $238 \mathrm{~nm}$ using UV Spectrophotometer. The percentage drug release was calculated [5].

\section{In vivo evaluation}

In vivo studies were performed on groups of four male wistar rats weighing $200 \pm 20 \mathrm{~g}$ with no signs of disease. All animals were maintained according to IAEC (Institutional Animal Ethics Committee, Belgaum, India) guidelines.

Group of animals:

Group 1: IV pure lovastatin

Group 2: oral pure lovastatin

Group 3: oral lovastatin nanocrystal $\left(\mathrm{F}_{1}\right)$

Group 4: oral lovastatin nanocrystal $\left(\mathrm{F}_{2}\right)$

\section{Dose for animal study}

Dose $(\mathrm{mg} / 200 \mathrm{~g}$ of rat $)=$ Human dose $(\mathrm{mg})$ x Body surface area

Dose $(\mathrm{mg} / 200 \mathrm{~g}$ of rat $)=10 \times 0.018$

Dose $(\mathrm{mg} / 200 \mathrm{~g}$ of rat $)=0.18 \mathrm{mg} / 200 \mathrm{~g}$ rat

For $220 \mathrm{~g}$ rat : Dose $=\frac{0.18 \times 220}{200}=0.198 \mathrm{mg} / 220 \mathrm{~g}$ rat

\section{Drug plasma study}

All animals were kept under fasting over night prior to experiment. For each animal, the formulation was suspended in methyl cellulose $(0.5 \% \mathrm{w} / \mathrm{v})$ to obtain $1 \mathrm{mg} / \mathrm{ml}$ lovastatin and this suspension was ultrasonicated for $2 \mathrm{~min}$, just before oral dosing in each experiment. Pure drug was also treated same as above. Each formulation and pure drug suspension was administered orally to four rats by oral feeding needle. The blood samples were withdrawn by retro orbital venous plexus puncture at 5, 30,60, 90, 120, 150, 180, 210 and $240 \mathrm{~min}$ for oral and IV control group and 5, 30, 60, 90, 120, 150, 180, 210, 240, $300,360,420$ and 480 min for $F_{1}$ and $F_{2}$ formulation. All the samples were collected in heparinized Eppendorf tubes and centrifuged (5000 $\mathrm{rpm}, 15 \mathrm{~min}$ ), and plasma was collected and stored at $-20^{\circ} \mathrm{C}$ until analysis. Owing to the instability of lovastatin in rat plasma at ambient temperature, all sample preparations were performed on an ice water bath [7] The drug plasma concentration was analyzed by a modification of HPLC technique.

HPLC analysis: Quantitative estimation of lovastatin was done by Mayura 3100 HPLC. The chromatographic system consisted of a solvent delivery pump equipped with a $20 \mu \mathrm{l}$ loop and a UV visible detector. A Sepralyte C-18 column $(50 \times 4.63 \mu \mathrm{m})$ was used. An aqueous buffer $(0.05 \mathrm{M}$ ammonium phosphate and $0.01 \mathrm{M}$ phosphoric acid buffer and acetonitrile) (50:50) was used as the mobile phase [7].

The mobile phase was delivered at a flow rate of $1.5 \mathrm{ml} / \mathrm{min}$, single injection volume was $20 \mu \mathrm{l}$ and the effluent was monitored at $238 \mathrm{~nm}$. 
Citation: Nanjwade BK, Derkar GK, Bechra HM, Nanjwade VK, Manvi FV (2011) Design and Characterization of Nanocrystals of Lovastatin for Solubility and Dissolution Enhancement. J Nanomedic Nanotechnol 2:107. doi:10.4172/2157-7439.1000107

\section{Linearity}

Separate stock solution of lovastatin was prepared in acetonitrile, in order to get a concentration of $2 \mathrm{mg} / 50 \mathrm{ml}$. Dilutions were made in acetonitrile to give working range of $1 \mu \mathrm{g} / \mathrm{ml}$ to $5 \mu \mathrm{g} / \mathrm{ml}$ and analyzed on HPLC.

\section{Data analysis}

The area under plasma drug concentration over time curve $\left(\mathrm{AUC}_{0-\mathrm{t}}\right)$ was calculated by relative/absolute bioavailability [8].

$\begin{aligned} \text { Relative bioavailability }= & \frac{\mathrm{AUC}_{0-\mathrm{t}} \text { of oral formulation of drug }}{\mathrm{AUC}_{0-\mathrm{t}} \text { of oral free drug }} \\ & \times \frac{\text { Dose of oral free drug }}{\text { Dose of oral formulation of drug }}\end{aligned}$

Absolute bioavailability $=\frac{\mathrm{AUC}_{0-\mathrm{t}} \text { of oral formulation of drug }}{\mathrm{AUC}_{0-\mathrm{t}} \text { of i.v. free drug }}$

$$
\times \frac{\text { Dose of i.v. free drug }}{\text { Dose of oral formulation of drug }}
$$

\section{Stability study}

Stability testing is performed to ensure that drug products retain their fitness for use until the end of their expiration dates. Information on the stability of drug substance is an integral part of the systemic approach to stability evaluation. The purpose of stability testing is to provide evidence on how the quality of a drug substance or drug product varies with time under influence of variety of environmental factors such as temperature, humidity and light. Stability study was performed on selected formulation $\mathrm{F}_{1}$ at $4^{\circ}, 30^{\circ} \pm 2^{\circ} / 65 \% \pm \% \mathrm{RH}$ and $40^{\circ} \pm 2^{\circ} / 65 \% \pm 5 \% \mathrm{RH}$. Percent drug content and in vitro release studies were performed [9].

\section{Results}

Surface morphology of the formed crystals was determined by using SEM and was found that crystalline nature of all the formulations remains with slight change in crystallinity. The SEM images of pure LVS and $F_{1}, F_{2}$ and $F_{3}$ are shown in Figure 1, 2, 3 and 4.

Particle size analyses of all the formulations were done by using particle size analyzer (Nanotrac 150 US). This evaluation was mainly carried out to check the effect of different solvents on particle size and it was found that the smallest particle size was observed in formulation $\mathrm{F}_{1}$ and $\mathrm{F}_{2}$ as compared to $\mathrm{F}_{3}$ formulation. This is might be due to the use of less concentration of drug in solvent, 50 times dilution of drug organic solution in water and due to the use of acetone and methanol as a solvent which is supported by the literature.

Particle size analysis graph of pure LVS and all formulations was shown in Table 1. $\mathrm{F}_{1}$ and $\mathrm{F}_{2}$ formulation has average particle size 579.33 $\mathrm{nm}$ and $584.58 \mathrm{~nm}$, while $\mathrm{F}_{3}$ have average particle size $803.71 \mathrm{~nm}$ respectively.

PXRD can provide useful information about the crystalline nature of the drug when formulated as nanocrystal. The formulations that were prepared evaluated for crystalline state of each formulation to check whether there is change in nature of drug after formulation in three different solvent.

The PXRD patterns of pure LVS and all formulations $\left(\mathrm{F}_{1}\right.$ to $\left.\mathrm{F}_{3}\right)$ are presented in Figure 5. The PXRD patterns of pure LVS showed numerous sharp peaks, which are the characteristic of a crystalline compound.
Drug crystallinity peaks were also detectable in formulation. Compared with the PXRD patterns of pure LVS and other formulation, the PXRD patterns of pure drug lovastatin has highest peak (253) at $2 \theta$ range of 13.995, other peaks were (207) at $2 \theta$ range of 24.910, (135) at $2 \theta$ range of 26.740 and (193) at $2 \theta$ range of 28.270 . While $F_{1}$ prepared by the addition of acetone has highest peak (67) at $2 \theta$ range of 26.240 ,

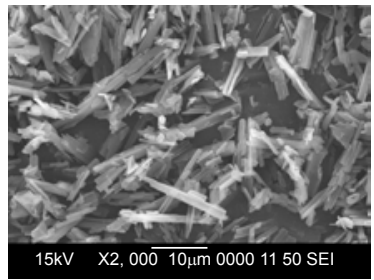

Figure 1: Scanning electron micrograph of pure lovastatin.

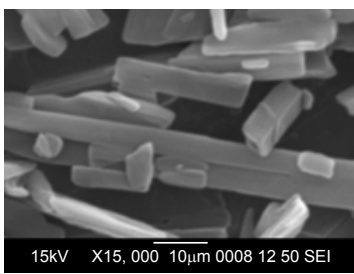

Figure 2: Scanning electron micrograph of $F_{1}$ formulation.

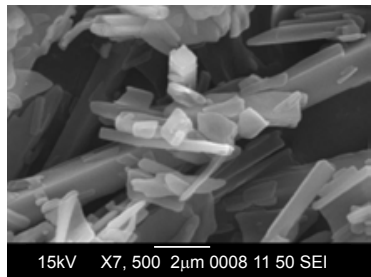

Figure 3: Scanning electron micrograph of $F_{2}$ formulation.

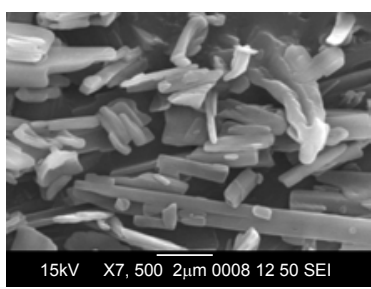

Figure 4: Scanning electron micrograph of $F_{3}$ formulation.

\begin{tabular}{|l|l|l|}
\hline Sr. no & Formulation code & Mean particle size $(\mathbf{n m})$ \\
\hline 1 & $\mathrm{~F}_{1}$ & $579.33 \pm 1.021$ \\
\hline 2 & $\mathrm{~F}_{2}$ & $584.58 \pm 1.013$ \\
\hline 3 & $\mathrm{~F}_{3}$ & $803.71 \pm 1.032$ \\
\hline
\end{tabular}

$\mathrm{nm}$ is nanometer, SD is standard deviation for $\mathrm{n}=3$ observations

Table 1: Average particle size of Ivs nanocrystal formulation.

\begin{tabular}{|l|l|l|l|l|l|}
\hline Sr. no. & $\begin{array}{l}\text { Solvent } \\
\text { used }\end{array}$ & \multicolumn{4}{|l|}{ Solubility in each solvent $(\mathbf{m g} / \mathbf{m l})$} \\
\hline 1. & Pure LVS & $\mathbf{F}_{1}$ & $\mathbf{F}_{2}$ & $\mathbf{F}_{3}$ \\
\hline 2. & $\begin{array}{l}\text { Distilled water } \\
\text { Acid buffer } \\
\left(\mathrm{P}^{\mathrm{H}} 1.2\right)\end{array}$ & $0.005 \pm 0.01$ & $0.092 \pm 0.02$ & $0.090 \pm 0.05$ & $0.081 \pm 0.01$ \\
\hline 3. & $\begin{array}{l}\text { Phosphate } \\
\left.\text { buffer ( } \mathrm{PH}^{\mathrm{H}} 7.4\right)\end{array}$ & $0.008 \pm 0.02$ & $0.176 \pm 0.01$ & $0.173 \pm 0.01$ & $0.134 \pm 0.04$ \\
\hline
\end{tabular}

$\mathrm{SD}$ is standard deviation for $\mathrm{n}=3$ observations

Table 2: Solubility determination of all formulations \& pure drug in each solvent. 
Citation: Nanjwade BK, Derkar GK, Bechra HM, Nanjwade VK, Manvi FV (2011) Design and Characterization of Nanocrystals of Lovastatin for Solubility and Dissolution Enhancement. J Nanomedic Nanotechnol 2:107. doi:10.4172/2157-7439.1000107

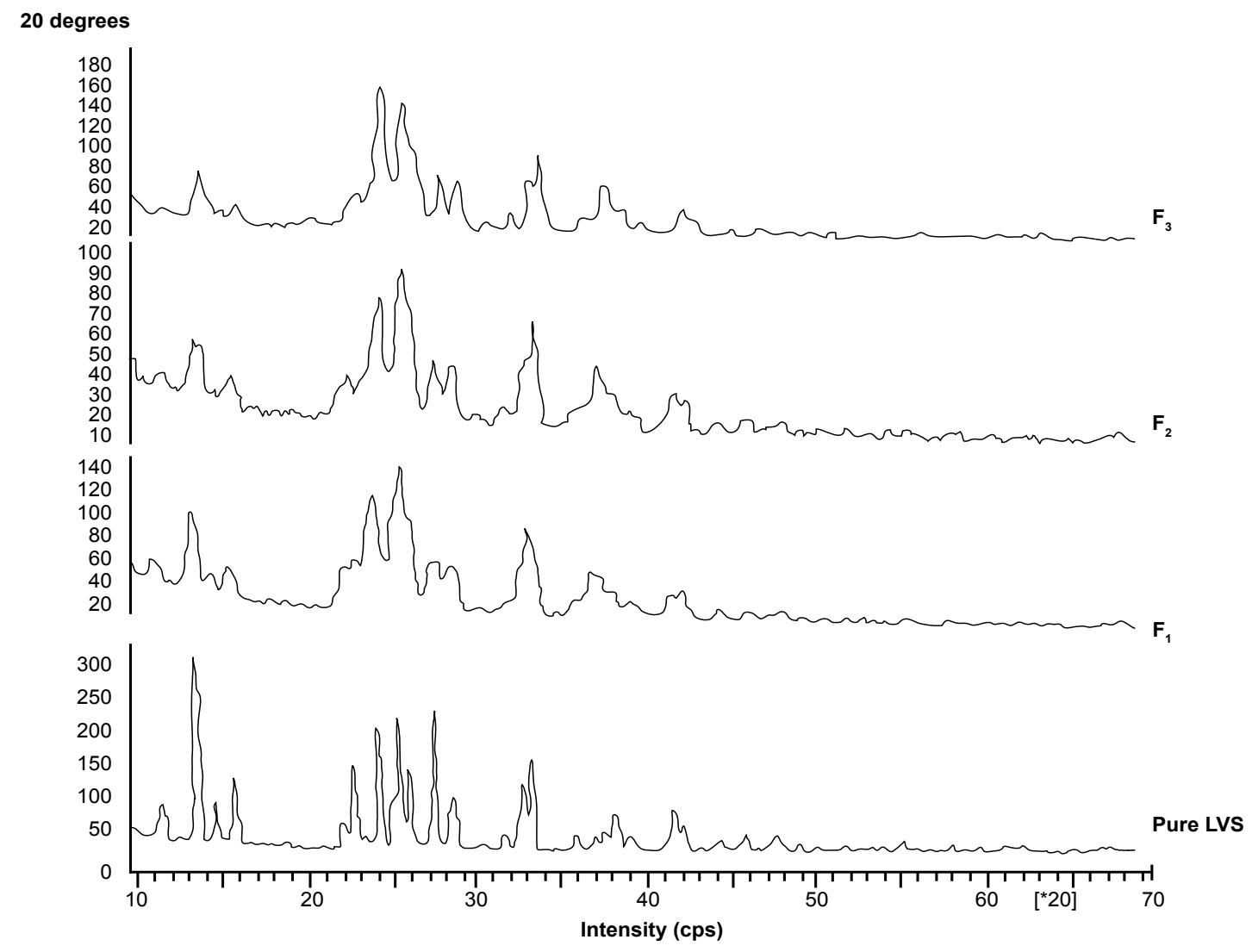

Figure 5: PXRD patterns of pure lovastatin and all formulations.

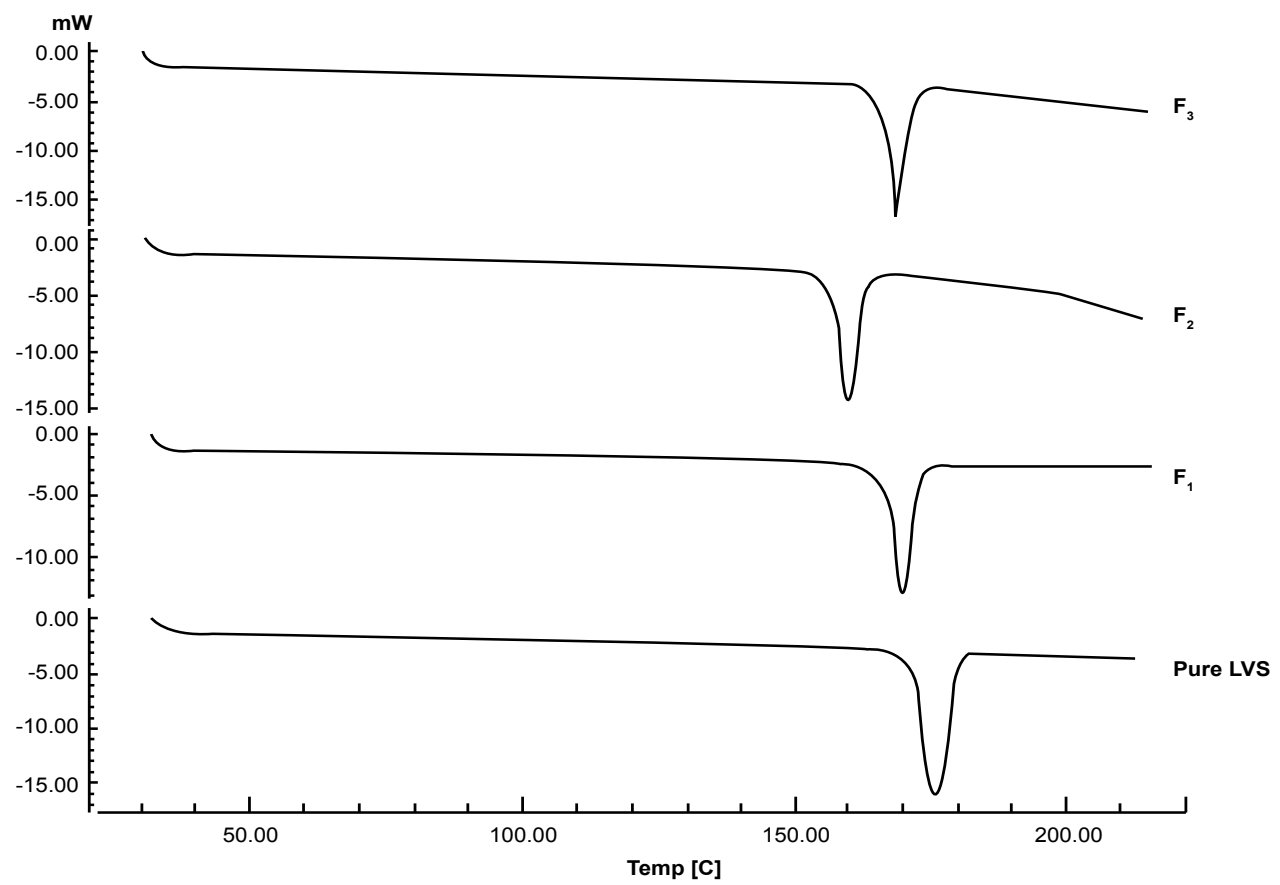

Figure 6: DSC patterns of pure lovastatin and all formulations. 
Citation: Nanjwade BK, Derkar GK, Bechra HM, Nanjwade VK, Manvi FV (2011) Design and Characterization of Nanocrystals of Lovastatin for Solubility and Dissolution Enhancement. J Nanomedic Nanotechnol 2:107. doi:10.4172/2157-7439.1000107

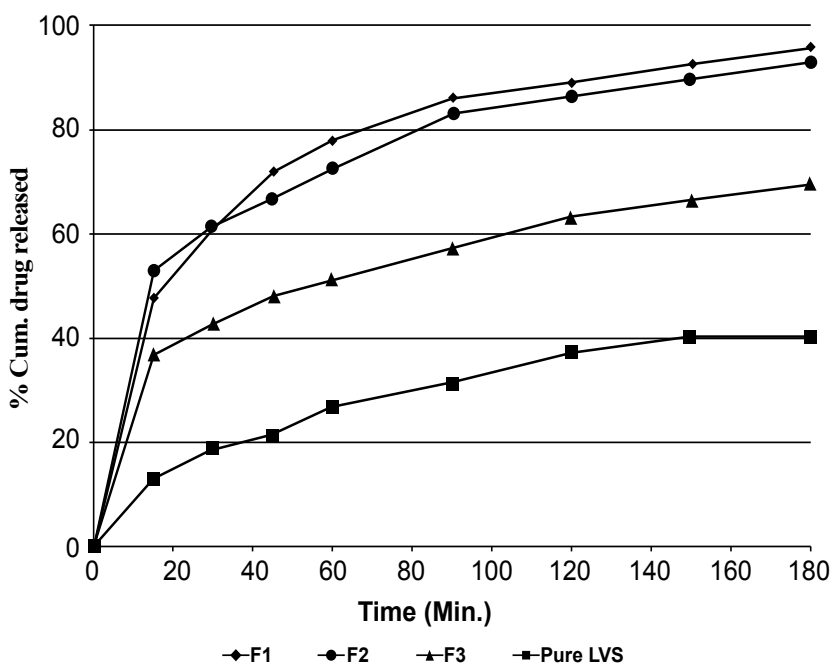

Figure 7: In vitro drug release pattern of pure lovastatin and all formulations.

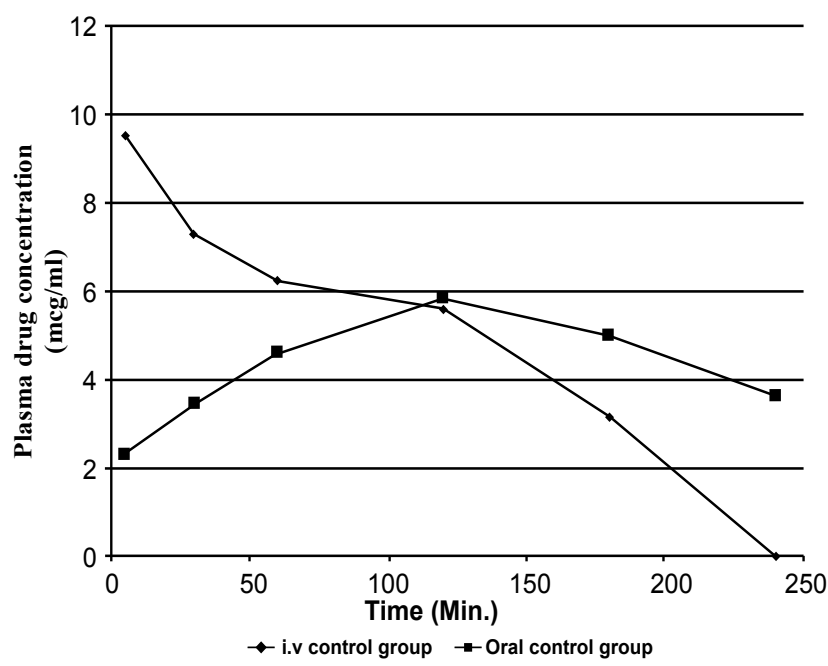

Figure 8: Blood plasma study of oral and IV administered pure lovastatin.

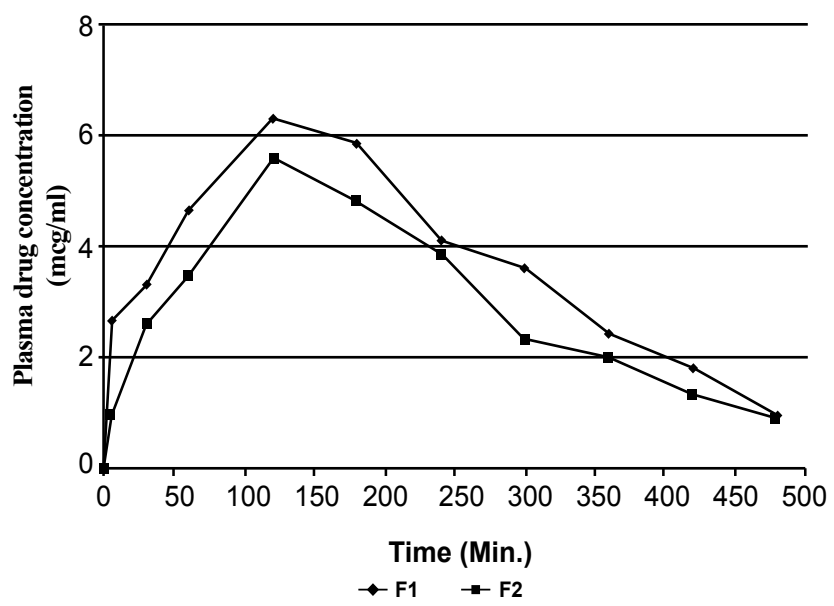

Figure 9: Blood plasma study of oral administered $F_{1}$ and $F_{2}$ formulation.

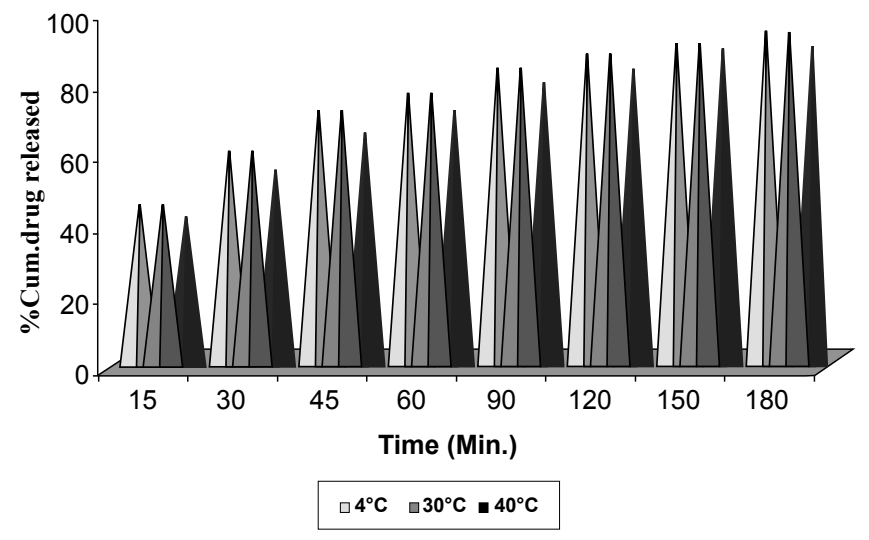

Figure 10: Drug release study of $F_{1}$ formulation for stability evaluation.

\begin{tabular}{|c|c|c|c|c|c|}
\hline $\begin{array}{l}\text { Formulation } \\
\text { code }\end{array}$ & $\begin{array}{l}\text { Absolute } \\
\text { bioavailability } \\
\text { ( } \mu \mathrm{g} / \mathrm{ml})\end{array}$ & $\begin{array}{l}\text { Relative } \\
\text { bioavailability } \\
\text { ( } \mu \mathrm{g} / \mathrm{ml})\end{array}$ & $\begin{array}{l}\text { Area under } \\
\text { curve(0-8) } \\
\text { ( } \mu \mathrm{g} / \mathrm{ml} . \mathrm{hrs})\end{array}$ & $\begin{array}{l}\text { Cmax } \\
(\mu \mathrm{g} / \mathrm{ml})\end{array}$ & $\begin{array}{l}\text { Tmax } \\
\text { (hrs.) }\end{array}$ \\
\hline $\begin{array}{l}\text { Oral control } \\
\text { group }\end{array}$ & ---- & ---- & 802.8 & $\begin{array}{l}5.849 \pm \\
0.245\end{array}$ & 2 \\
\hline $\begin{array}{l}\text { IV control } \\
\text { group }\end{array}$ & ---- & ---- & 986.7 & $\begin{array}{l}9.546 \pm \\
0.094\end{array}$ & $5^{\mathrm{a}}$ \\
\hline$F_{1}$ & 0.826 & 1.015 & 815.3 & $\begin{array}{l}6.325 \pm \\
0.324\end{array}$ & 2 \\
\hline$F_{2}$ & 0.821 & 1.010 & 810.9 & $\begin{array}{l}5.590 \pm \\
0.432\end{array}$ & 2 \\
\hline
\end{tabular}

$\mathrm{SD}$ is standard deviation for $\mathrm{n}=3$ observations

Table 3: Comparison for bioavailability of lovastatin nanocrystal.

Formulation Percent drug Percent drug content at Percent drug content at code content at $4^{\circ} \mathrm{C} 30^{\circ} \mathrm{C} \pm 2^{\circ} \mathrm{C} / 65 \% \pm 5 \% \mathrm{RH} \quad 40^{\circ} \mathrm{C} \pm 2{ }^{\circ} \mathrm{C} / 65 \% \pm 5 \% \mathrm{RH}$ \begin{tabular}{l|l|l|l}
$\mathrm{F}_{1}$ & $66.46 \%$ & $66.32 \%$ & $60.54 \%$
\end{tabular}

Table 4: Drug content after 30 days storage of selected formulation $\left(F_{1}\right)$.

other peaks were (55) at $2 \theta$ range of $25.710,(41)$ at $2 \theta$ range of 33.625 indicating the semi crystalline nature of the drug in formulation. $\mathrm{F}_{2}$ also has highest peak (76) at $2 \theta$ range of 25.625 , other peaks were (64) at $2 \theta$ range of 26.185 , (59) at $2 \theta$ range of 24.385 indicating the semi crystalline nature of the drug in formulation due to the addition of methanol. $\mathrm{F}_{3}$ also has highest peak (154) at $2 \theta$ range of 24.440 , other peaks were (125) at $2 \theta$ range of $25.735,(83)$ at $2 \theta$ range of 26.305 indicating the slight change in crystallinity of the drug in formulation, and indicating the semi crystalline nature of the drug due to addition of acetonitrile as a solvent. Moreover, no other peaks than those that could be assigned to the pure LVS were detected in the formulation, thus indicating the absence of chemical instability in the solid state. These results confirm that LVS is present as a crystalline material.

Differential Scanning Calorimetry (DSC) can be used to investigate and predict the changes in crystalline form of the drug.

Polymorphism is the capability of a substance to crystallize into two or more different crystalline forms. Any polymorphic changes in the drug may change its melting point, bioavailability, and release kinetics. The polymorphic change in the drug, lovastatin, was also studied using differential scanning calorimetry (DSC) by testing the melting characteristics of the drug. Figure 6 compares the DSC thermograms of lovastatin pure drug and all formulations.

Lovastatin showed a large and sharp characteristic endothermic peak at $175.19^{\circ}$ due to its phase transition. The onset and endset of phase transition of lovastatin were observed at $171.44^{\circ}$ and $180.59^{\circ}$ respectively. 
Citation: Nanjwade BK, Derkar GK, Bechra HM, Nanjwade VK, Manvi FV (2011) Design and Characterization of Nanocrystals of Lovastatin for Solubility and Dissolution Enhancement. J Nanomedic Nanotechnol 2:107. doi:10.4172/2157-7439.1000107

DSC thermogram of formulation $\mathrm{F}_{1}$ showed an endothermic peak at $173.92^{\circ} \mathrm{C}$ corresponding to the slight change in the crystalline nature.

DSC thermograms of other two formulations $\left(\mathrm{F}_{2}\right.$ and $\left.\mathrm{F}_{3}\right)$ showed a small and sharp characteristic endothermic peak at $174.87^{\circ}$ and $174.57^{\circ}$ respectively.

The DSC thermograms of all formulations showed characteristic endothermic peaks corresponding to those of the pure drug and there is no appearance of one or more new peak or disappearance of one or more peak corresponding to those of the pure drug. This indicates that crystalline nature remains, with slight change in crystallinity due to change in melting point. Besides this, no additional peaks were found to demonstrate the significant changes in the melting characteristics of lovastatin in the formulation indicating no polymorphic changes in the lovastatin

The peaks were found to be nearly identical, with a calculated $\Delta \mathrm{H}$ of pure drug, $\mathrm{F}_{1}, \mathrm{~F}_{2}$ and $\mathrm{F}_{3}$ were around $-96.68 \mathrm{~J} / \mathrm{g},-70.45 \mathrm{~J} / \mathrm{g},-81.14 \mathrm{~J} / \mathrm{g}$ and $-86.65 \mathrm{~J} / \mathrm{g}$ respectively.

The improvement in solubility of LVS nanocrystal formulations is shown in Table 2. $F_{1}$ and $F_{2}$ showed highest solubility in water $(0.092$ $\mathrm{mg} / \mathrm{ml}$ and $0.090 \mathrm{mg} / \mathrm{ml}$ respectively), as compared with plain LVS $(0.005 \mathrm{mg} / \mathrm{ml})$ which are 18.4 fold and 18 fold greater than pure LVS respectively and $\mathrm{F}_{3}$ formulation of LVS was also shown to enhance the solubility of LVS in water which is 16.2 fold greater than pure LVS but less than $\mathrm{F}_{1}$ and $\mathrm{F}_{2}$.

The solubility of formulation $\mathrm{F}_{1}, \mathrm{~F}_{2}$ and $\mathrm{F}_{3}$ in $\mathrm{P}^{\mathrm{H}} 1.2$ buffer were 0.148 $\mathrm{mg} / \mathrm{ml}, 0.131 \mathrm{mg} / \mathrm{ml}$ and $0.097 \mathrm{mg} / \mathrm{ml}$ respectively. Thus the solubility of LVS was improved 21.14 fold, 16.37 fold, and 13.85 fold respectively compared to pure LVS.

Upon size reduction of LVS by precipitation method, the solubility of formulation $\mathrm{F}_{1}, \mathrm{~F}_{2}, \mathrm{~F}_{3}$ in $\mathrm{P}^{\mathrm{H}} 7.4$ buffer were $0.186 \mathrm{mg} / \mathrm{ml}, 0.183 \mathrm{mg} /$ $\mathrm{ml}$ and $0.159 \mathrm{mg} / \mathrm{ml}$ respectively, which were 23.25 fold, 22.87 fold and 19.87 fold respectively.

The release profile of a drug predicts how a delivery system might function and gives valuable insight into its in vivo behavior. All the formulations of lovastatin were subjected to in vitro release studies and were compared with the release of pure drug lovastatin. These in vitro release studies were carried out using $\mathrm{P}^{\mathrm{H}} 1.2$ buffer and $\mathrm{P}^{\mathrm{H}} 7.4$ buffer as the dissolution medium.

The drug release data obtained for all formulations and pure drug is shown in Figure 7 which shows the plot of cumulative percent drug released as a function of time for pure LVS and formulation $\mathrm{F}_{1}$ to $\mathrm{F}_{3}$.

From the results of in vitro release study, it was observed that the batch $F_{1}$ and $F_{2}$ gave highest percent cumulative drug release which might be due to the use of acetone and methanol as a solvent than that in $\mathrm{F}_{3}$ and pure drug. These batches $\left(\mathrm{F}_{1}\right.$ to $\left.\mathrm{F}_{3}\right)$ gave the drug release of $95.69 \%, 92.80 \%$ and $69.50 \%$ in 3 hours respectively. From this study it was evaluated that, as the concentration of drug decreased and the change in type of solvent use, drug release was increased.

These finding were supported by study of Prasad et al. who reported that acetone and methanol generally yielded less particle size and increased release rate ${ }^{4}$. It was found that cumulative percent drug release of all formulations were increase due to particle size reduction as compared to pure drug after $3 \mathrm{~h}$. Further the use of type of solvent and concentration of drug also affect the drug release. Use of acetone and methanol as a solvent in formulation $\mathrm{F}_{1}$ and $\mathrm{F}_{2}$ respectively showed increase release rate of lovastatin when compared to $\mathrm{F}_{3}$ formulation and pure drug.

All formulations showed an initial burst release. In the first 15 min, drug released was $47.60 \%, 52.90 \%$, and $37.10 \%$ for $\mathrm{F}_{1}, \mathrm{~F}_{2}$, and $\mathrm{F}_{3}$ respectively. The slow increase in release rate in the later stage can be attributed to the slight saturation of the drug in the dissolution medium. The initial burst release of lovastatin can be due to the less particle size and also the use of sodium lauryl sulphate (SLS) as a surfactant, which lowers the surface tension around the drug particle. When the drug particle comes in contact with SLS, it lowers the surface tension and it results in to solvation of drug particle in the dissolution medium.

It is generally accepted that the dissolution media are not completely representative of gastrointestinal conditions, yet it is proposed in guidelines that a good method will use a dissolution media that is physiologically meaningful or closely mimics in vivo conditions $[10,11]$. It has been suggested that the inclusion of surface active agents in dissolution media is important for poorly soluble compounds because the lack of surface tension-lowering agents would result in poorer wetting and in vitro dissolution rates that are not representative of in vivo rates [12]. FDA has promoted the use of surfactants in media for conducting dissolution studies of poorly soluble compounds $[13,14]$ Dissolution studies of pure LVS and all other nanocrystal formulations were carried out in dissolution media $\left(\mathrm{P}^{\mathrm{H}} 1.2\right.$ buffer and phosphate buffer $\left.\mathrm{P}^{\mathrm{H}} 7.4\right)$ containing aqueous sodium lauryl sulfate solution $(0.25 \%$ $\mathrm{w} / \mathrm{v}$ ) because sodium lauryl sulfate showed minimal surface tension at $0.2 \%$ with no significant change at higher concentrations $[15,16]$. When the LVS was dispersed on the surface of the aqueous surfactant solution, LVS rapidly left the surface and was dispersed in the bulk of solution, which indicates wetting of LVS, unlike pure water.

The formulation $\mathrm{F}_{1}$ and $\mathrm{F}_{2}$ which are formulated using acetone and methanol as a solvent enhanced the dissolution rate of LVS significantly (90-100\% in both dissolution media) within $3 \mathrm{~h}$. Hence, the faster dissolution of LVS from the $\mathrm{F}_{1}$ and $\mathrm{F}_{2}$ formulation is attributed to the particle size reduction. In addition, other factors such as the absence of aggregation and agglomeration between hydrophobic drug particles, good wettability, and dispersibility of the dispersed drug also might have contributed to the observed increase in the dissolution rate of LVS from the nanocrystal formulation [17].

The dissolution rate of LVS from all the formulations was significantly higher than that of pure LVS within $3 \mathrm{~h}$. The in vitro release profile of all formulations $\left(\mathrm{F}_{1}\right.$ to $\left.\mathrm{F}_{3}\right)$ was compared with pure drug of lovastatin. The drug releases were found to be $95.69 \%, 92.80 \% 69.50 \%$ and $40.46 \%$ for formulations $\mathrm{F}_{1}, \mathrm{~F}_{2}$ and $\mathrm{F}_{3}$ and pure drug respectively after 3 hours. Results show that, using the nanocrystal formulations $F_{1}$ to $\mathrm{F}_{3}$ when compared to pure drug release significantly increases the drug release.

Two formulations $\mathrm{F}_{1}$ and $\mathrm{F}_{2}$ were selected to measure oral bioavailability of the drug. The curve was found to be linear in the range of $1-5 \mu \mathrm{g} / \mathrm{ml}$ at wavelength $238 \mathrm{~nm}$. The regression value was found to be 0.9994 .

The blood plasma study of oral administered pure drug (control group), shown in Figure 8, the drug was detected within $5 \mathrm{~min}$ in plasma. In case of i. v. pure drug (control group) showed that the plasma drug concentration declined rapidly after 5 min until up to $4 \mathrm{~h}$ no drug could be detected in plasma.

Single oral administration of drug nanocrystal was detectable in blood plasma from $5 \mathrm{~min}$ up to $8 \mathrm{~h}$ as shown in Figure 9. Thus it is 
Citation: Nanjwade BK, Derkar GK, Bechra HM, Nanjwade VK, Manvi FV (2011) Design and Characterization of Nanocrystals of Lovastatin for Solubility and Dissolution Enhancement. J Nanomedic Nanotechnol 2:107. doi:10.4172/2157-7439.1000107

indicated that, it was possible to have an increased release of lovastatin drug by forming nanocrystal. In both formulation $\mathrm{F}_{1}$ and $\mathrm{F}_{2}, \mathrm{~F}_{1}$ showed more concentration in plasma than $\mathrm{F}_{2}$ and total area under curve was found more than $\mathrm{F}_{2}$

The absolute relative bioavailability of oral nanocrystal was determined by taking the area under curve of pure drug i.v. administration and oral administration of pure drug and formulation $\mathrm{F}_{1}$ and $\mathrm{F}_{2}$ as shown in Table 3. The results revealed that absolute and relative bioavailability was slightly increased as compared to oral control group; it was found that relative bioavailability was 1.015 and 1.010 respectively.

Stability studies of the prepared nanocrystals were carried out, by storing formulation $\mathrm{F}_{1}$ at $4^{\circ} \mathrm{C}$ in refrigerator, at $30^{\circ} \pm 2,65 \% \pm 5 \%$ $\mathrm{RH}$ and at $40^{\circ} \pm 2^{\circ} / 65 \% \pm 5 \% \mathrm{RH}$ in humidity control oven for thirty days. Two parameters namely residual percent drug content and in vitro release studies were carried out. The results of drug content after 30 days of stability testing at different storage conditions are shown in Table 4. In vitro dissolution for the same formulation is also shown in Figure 10. On comparing this data with the previous release data of $F_{1}$, it was observed that there is slight decrease in the drug release. These results may be due to oxidation of lovastatin formulation to some extent during storage.

As shown in Table 4, formulation $\mathrm{F}_{1}$ showed slight decrease in drug content at $30^{\circ} \mathrm{C}(66.32 \%)$ and $4^{\circ}(66.46 \%)$ after 30 days of storage whereas at $40 \pm 2^{\circ}$ the formulation $\mathrm{F}_{1}$ showed significant decrease in the drug content $(60.54 \%)$ after 30 days of storage. This significant decrease in drug content is due to the slight oxidation of drug in both formulations at temperature $\left(40^{\circ} \mathrm{C}\right)$.

The in vitro drug release from formulation $\mathrm{F}_{1}$ was slightly decreased at $30^{\circ} \mathrm{C}(93.06 \%)$ and $4^{\circ}(93.76 \%)$ after 30 days of storage whereas at $40 \pm 2^{\circ}(89.30 \%)$, the formulation $\mathrm{F}_{1}$ shows significant decrease in drug release. The precipitation of drug in formulation $\mathrm{F}_{1}$ at $40^{\circ} \mathrm{C}$ leads to decrease in drug content resulting in decreased drug release from the above formulations.

From the stability studies it was confirmed that nanocrystal formulations of lovastatin remained more stable at $4^{\circ} \mathrm{C}$ and at $30^{\circ} \mathrm{C}$ temperature and humidity. The maximum instability of nanocrystal formulations was observed at $40 \pm 2^{\circ}$.

\section{Discussion}

From the above experimental results it can be concluded that, acetone and methanol are the suitable solvents for the preparation of LVS nanocrystal. $F_{1}$ showed maximum practical yield and less particle size at low concentration of drug in solvent. The results states that decreasing the concentration of drug in solvent decreases the particle size and increases the solubility and release rate. From the particle morphology by SEM, it was observed that LVS nanocrystals remain crystalline. Particle size for the formulation $F_{1}$ showed the smallest particle size at $3 \mathrm{mM}$ concentration of drug. PXRD and DSC data revealed that there is a semi crystalline nature in $F_{1}, F_{2}$ and $F_{3}$ formulations as compared to pure LVS. The in vitro release studies showed biphasic release pattern for all the formulations, with an initial burst effect, which may be attributed to the increase in contact of the drug particle to the dissolution medium due to the increase in surface area of the particle. On the basis of particle morphology, particle size analysis and in vitro release, formulation $\mathrm{F}_{1}$ was selected as an optimum formulation for the in vivo and stability studies. In vivo study revealed that the oral bioavailability of formulation $\mathrm{F}_{1}$ and $\mathrm{F}_{2}$ was increased. Stability study of selected formulation $\mathrm{F}_{1}$, showed slight changes in drug content and identical in vitro release profile was found in formulation at $4^{\circ}$ and at $30^{\circ} \mathrm{C}$ storage. Thus it can be concluded that $4^{\circ} \mathrm{C}$ and $30^{\circ} \mathrm{C}$ is the most suitable temperature for storage of lovastatin nanocrystal.

From the above studies it is revealed that present work was a satisfactory preliminary study of improving bioavailability of lovastatin. Further detailed investigations and in vivo-in vitro correlation need to be established to guarantee the efficiency and bioavailability of the formulation and it can be a promising tool in the treatment of hypercholesterolemia. Further studies on improving bioavailability have to be carried out with the use of different method for the production of nanocrystals.

From the above studies it is evident that a promising novel conventional oral formulation of lovastatin can be developed. Further detailed investigations are required to establish efficacy of these formulations.

\section{Acknowledgement}

Kreb's Biochemical pvt. Ltd. Hyderabad is acknowledged for the generous gift of lovastatin.

\section{References}

1. Loftsson T, Hreinsdottir D (2005) Masson Mar. Evaluation of Cyclodextrin solubilization of drugs. Int J Pharm 302: 18-28.

2. Tufts center for the study of drug development (2001) Tufts University, Boston Mass USA: http://csdd.tufts.edu.in

3. Muller RH, Bohm BHL (1998) Nanosuspensions, in Emulsions \& Nanosuspensions for the formulation of poorly soluble drugs. Muller R.H. Bentia S., and Bohm B.H.L. Eds. (Medpharm Scientific Publishers), Stuttgart, Germany.

4. Prasad N, Pudavar HE, Baba Koichi, Roy I, Ohulchansky T, et al. (2007) Method for delivering hydrophobic drugs via nanocrystal. United States Patent 0134340.

5. Deleers M, Hecq J, Fanara D, Vranckx H, Amighi K (2005) Preparation and characterization of nanocrystals of nifedipine for solubility and dissolution rate enhancement. Int J Pharm 299: 167-177.

6. Nti-Gyabaah J, Chmielowski R, Chan V, Chiw YC (2008) Solubility of lovastatin in a family of six alcohols: Ethanol, 1-propanol, 1-butanol, 1-pentanol, 1-hexanol and 1-ioctanol. Int J Pharm 359: 111-117.

7. Gande Suresh, Majunath K, Venkateswarlu, Satyanarayana V (2007) Preparation, Characterization, and in vitro, in vivo evaluation of lovastatin solid lipid nanoparticles. AAPS PharmSciTech 8: 24

8. Hidalgo IJ, Rhodes JR, Marietta MP, Dobson GL, Luo Y, et al. (2000) Estimation of oral bioavailability in the rat by the accelerated infusion technique. J Pharm Pharmacol 52: 957-961.

9. ICH QIA (R2) (2003) Stability testing guidelines: Stability testing of new drug substances and products. The European agency for the evaluation of medicinal products. CPMP/ICH/273/99:4-20.

10. Horter D, Dressman JB (1997) Influence of physiochemical properties on dissolution of drugs in the gastrointestinal tract. Adv Drug Deliv Rev 25: 3-14.

11. Skelly JP, Buskirk V, Arbit HM, Amidon GL, Augsburger L (1993) Scale up of immediate release oral solid dosage forms. J Parenter Sci Technol 47: 52-56.

12. Galia E, Horton J, Dressman JB (1999) Albendazole generics-a comparative in vitro study. Pharm Res 16: 1871-1875.

13. Noory C, Tran N, Ouderkirk L, Brown S, Perry J (1999) Rethinking the use of water as a dissolution medium. Dissolution Technol 6: 6-7.

14. Shah VP, Noory A, Noory C, McCullough B, Clarke S, (1995) In vitro dissolution of sparingly water-soluble drug dosage forms. Int $\mathrm{J}$ of Pharm 25: 99-106.

15. Barzegar-Jalali M, Maleki N, Garjani A, Khandar AA, Haji-Hosseinloo M, (2002) Enhancement of dissolution rate and anti-inflammatory effects of piroxicam using solvent deposition technique. Drug Dev Ind Pharm 28: 681-686.

16. Tang L, Khan SU, Muhmmad NA (2001) Evaluation and selection of biorelevant dissolution media for a poorly water soluble new chemical entity. Pharm Develop Technol 6: 531-540.

17. Vromans H, Eisson AC, Coenraad FL (1989) Mechanism of dissolution of drugcyclodextrin complexes. Drug Dev Ind Pharm 15: 250-255. 